\title{
EDUCAÇÃO FÍSICA E PSICOMOTRICIDADE: FATORES ASSOÇIADOS AO DESENVOLVIMENTO COGNITIVO INFANTIL
}

\author{
PHYSICAL EDUCATION AND PSYCHOCOMOTRICITY: FACTORS ASSOCIATED \\ WITH CHILD COGNITIVE DEVELOPMENT
}

\section{EDUCACIÓN FÍSICA Y PSICOCOMOTRICIDAD: FACTORES ASOCIADOS CON EL DESARROLLO COGNITIVO INFANTIL}

\author{
Natalie Santos Barbosa ${ }^{1}$ \\ Jeane Rodella Assunção²
}

\begin{abstract}
Resumo
A psicomotricidade pode ser entendida como campo de estudo multidisciplinar que busca a compreensão das relações do ser humano com o meio em que está inserido à medida que é moldado por suas práticas corporais e experienciais. Sendo assim, o principal objetivo é compreender a relação da psicomotricidade com a Educação Física no auxílio do desenvolvimento cognitivo infantil. Os procedimentos metodológicos foram baseados na revisão de literatura científica de livros e artigos, publicados entre 2010 e o ano de 2020, a fim de verificar o que há de mais recente e relevante a respeito dessa temática. A ciência da Psicomotricidade é importante para o desenvolvimento das áreas afetivas, motoras e cognitivas nas diferentes fases da vida, principalmente na infância, sendo assim, uma ferramenta importante no auxílio das aulas de Educação Física.
\end{abstract}

Palavras Chave: Educação Infantil; Educação Física; Psicomotricidade.

\begin{abstract}
Psychomotricity can be understood as a multidisciplinary field of study that seeks to understand the relationships of the human being with the environment in which he is inserted as it is shaped by his bodily and experiential practices. Thus, the main objective is to understand the relationship between psychomotricity and physical education in the aid of child cognitive development. The methodological procedures were based on the review of scientific literature of books and articles, published between 2010 and 2020, in order to verify the most recent and relevant on this theme. The science of Psychomotricity is important for the development of affective, motor and cognitive areas in different phases of life, especially in childhood, thus being an important tool in the aid of Physical Education classes.
\end{abstract}

Keywords: Early Childhood Education; Physical Education; Psychomotricity.

\section{Resumen}

\footnotetext{
${ }^{1}$ Graduanda em Educação Física pelo Centro Universitário Jorge Amado.

E-mail: natysalvador@hotmail.com

ORCID: http://orcid.org/0000-0002-0124-4862

2 Doutora em Ciências da Educação. Docente no Centro Universitário Jorge Amado, Centro Universitário Maurício de Nassau e Escola Municipal Julieta Calmon.

E-mail: janerodella@hotmail.com

ORCID: https://orcid.org/0000-0001-5367-1973
} 
La psicomotricidad puede entenderse como un campo de estudio multidisciplinario que busca comprender la relación entre el ser humano y el entorno en el que se inserta tal y como lo configuran sus prácticas corporales y vivenciales. Por tanto, el objetivo principal es comprender la relación entre la psicomotricidad y la Educación Física para ayudar al desarrollo cognitivo de los niños. Los procedimientos metodológicos se basaron en la revisión de la literatura científica de libros y artículos, publicados entre 2010 y 2020, con el fin de verificar la información más reciente y relevante sobre este tema. La ciencia de la Psicomotricidad es importante para el desarrollo de las áreas afectiva, motora y cognitiva en las diferentes etapas de la vida, especialmente en la infancia, siendo, por tanto, una herramienta importante en la ayuda de las clases de Educación Física.

Palavras clave: Educación Infantil; Educación Física; Psicomotricidad.

\section{Introdução}

A Psicomotricidade desde o seu surgimento até a atualidade pode ser acompanhada por marcos importantes onde vários estudiosos como Dupré, Henry Wallon e Ajuriaguerra, contribuíram para a caracterização da palavra (COSTA JR, 2017).

No final do século XIX, Phellipe Tissié, usou pela primeira vez o termo para nomear a região específica do cérebro encarregada por unir as funções do pensamento com funções motoras. Em 1925 Henry Wallon evidencia a relação existente entre o movimento, afeto, emoções e seus hábitos. Foi então que Julian Ajuriaguerra demarcou os transtornos psicomotores entre os neurológicos e os psiquiátricos. Em 1968, os primeiros cursos de pós graduação foram iniciados nas universidades brasileiras. Na década de 70, diversos profissionais trouxeram da Europa os conceitos e práticas sobre Psicomotricidade e a divisão nas abordagens reeducativa e terapêutica. A francesa Françoise Désobeau, trouxe ao Brasil uma abordagem exclusiva onde era feita a substituição das técnicas por jogos e brincadeiras. Em 1980 foi fundada a primeira Associação Brasileira de Psicomotricidade (ABP) (COSTA JR, 2017).

Santos e Cavalari (2010) definem a Psicomotricidade como uma ciência que estuda o homem através do seu corpo e os seus movimentos, juntamente com o mundo interno e externo. Sendo relacionada com o amadurecimento do corpo e as suas origens cognitivas, afetivas e orgânicas.

Fonseca (2010) entende a Psicomotricidade como a ciência de campo transdisciplinar que estuda e investiga as relações e as influências recíprocas 
e sistêmicas, entre o psiquismo e o corpo, e, entre o psiquismo e a motricidade, emergentes da personalidade total, singular e evolutiva que caracteriza o ser humano, nas suas múltiplas e complexas manifestações biopsicossociais, afetivo-emocionais e psicosociocognitivas.

Fonseca (2018) cita que a aprendizagem não acontece simplesmente pelo ouvir ou pelo pensar, e sim por meio de reações e atitudes adaptativas causadas pelo envolvimento com o mundo externo, ou seja, se trata de um processo corporificado, e motor.

Nas aulas de Educação Física a psicomotricidade desenvolve-se através de atividades que tenham uma visão holística do indivíduo, incentivando suas relações sociais e superação de limites, contribuindo para a formação de uma criança ativa e saudável, minimizando os problemas de aprendizagem (BESSA; MACIEL, 2016). Nesta perspectiva elaborou-se o seguinte problema de pesquisa: Como a psicomotricidade pode contribuir para o desenvolvimento cognitivo infantil através das aulas de educação física?

Neste contexto, este trabalho tem como objetivo geral compreender a relação da Psicomotricidade com a Educação Física no auxílio do desenvolvimento cognitivo infantil.

Especificamente pretende-se conceituar a Psicomotricidade, compreender a Psicomotricidade no desenvolvimento cognitivo infantil e debater as contribuições da Psicomotricidade nas aulas de Educação Física.

Esse estudo tem por foco de investigação as contribuições o auxílio da Psicomotricidade nas aulas de Educação Física e como isso implica no processo de desenvolvimento cognitivo infantil. Sendo a ciência da psicomotricidade importante para o desenvolvimento cognitivo, afetivo, e motor do indivíduo em diferentes fases da vida, principalmente na infância. Sabendo que é comum aos indivíduos que não tem as suas habilidades psicomotoras estimuladas, apresentar dificuldades no aprendizado de determinados conteúdos, e apresentar também alguma dificuldade na coordenação motora. 


\section{Metodologia}

O presente estudo foi realizado por meio de uma revisão bibliográfica. Foram selecionados 21 artigos e trabalhos científicos disponíveis para consulta em base de dados, tais como: livros, bancos de dados da Scielo e repositórios institucionais. As palavras: psicomotricidade, educação infantil, educação física e aprendizagem foram utilizadas como descritores de pesquisa para o desenvolvimento do estudo. A análise das referências inclui publicações no período de 2010 a 2020.

Para esta pesquisa foi feita uma busca exploratória de todos os materiais pesquisados e logo ocorreu a seleção dos artigos, verificando a relevância e o embasamento do conteúdo encontrado para o alcance dos objetivos e o corte temporal, para além disso as referências duplicadas foram excluídas. O processo foi finalizado por meio de uma leitura da qual pudesse relacionar a temática da pesquisa com a proposta encontrada no objetivo de pesquisa, possibilitando assim a construção de ideias próprias.

\section{Educação física e psicomotricidade}

\section{- Psicomotricidade: conceito e elementos psicomotores}

De acordo com Oliveira e Souza (2013) a Psicomotricidade pode ser entendida como uma ciência que estuda o indivíduo através de seu corpo em movimento juntamente com as suas relações internas e externas. O seu aprendizado tem como base três principais pontos que são: o movimento, o intelecto e o afeto.

"Psicomotricidade, portanto, é um termo empregado para uma concepção de movimento organizado e integrado, em função das experiências vividas pelo sujeito cuja ação é resultante de sua individualidade, sua linguagem e sua socialização." (ASSOCIAÇÃO BRASILEIRA DE PSICOMOTRICIDADE, 2019).

Fonseca (2018) traz sob sua perspectiva a psicomotricidade definida como um campo de atuação pluridisciplinar que estuda e investiga as relações entre psiquismo e a motricidade, entendendo o psiquismo como subdividido entre cognitivo e sócio 
afetivo enquanto a motricidade é entendida como um agrupamento de manifestações corpóreas e mentais que pode ser idealizada como um comportamento e como resposta adaptativa. A psicomotricidade só é encontrada em humanos, isso por conta da consciência de seu Eu, ou seja, o ser humano tem consciência e sabe que tem consciência e isso surge a partir das interações sociais e o desenvolvimento da sua cognição social (FONSECA, 2018).

A falta de um desenvolvimento adequado das habilidades psicomotoras acarreta em sérios problemas para a criança, dentre eles que pode-se destacar estão a escrita espelhada, noção espacial e lateralidade (INSTITUTO NEUROSABER, 2017). Os elementos psicomotores podem ser classificados da seguinte forma:

Elementos
Psicomotores
Coordenaço
Moton Ampla
Coordenaço
Motora Fine
Lateralidade
Equilibrio
Estruturaçăo
Espacial
Orientaçao
temporal
Fitmo

Figura 01: - Elementos Psicomotores.

\begin{tabular}{|c|c|}
\hline Definictio & Autor \\
\hline $\begin{array}{l}\text { Primeira oondicao a ser desenvolvida no espago infanti. E o } \\
\text { trabaiho que aperfeicoa os movimentos dos membros } \\
\text { superionese inferiores }\end{array}$ & Almeida (2007) \\
\hline 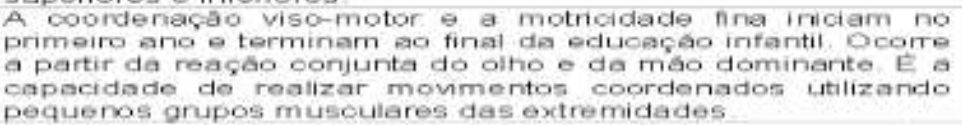 & $\begin{array}{l}\text { Le Boulch } \\
\text { (1986) }\end{array}$ \\
\hline 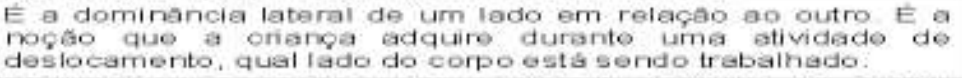 & $\begin{array}{c}\text { Meur e staes } \\
(1984)\end{array}$ \\
\hline $\begin{array}{l}\text { Hebilidade de onseng de manter o pontrole do como. } \\
\text { Utilizando ambos os lados ao mesmo tempo, apenas um lado } \\
\text { ou ambos alternademente. }\end{array}$ & Hurtado (1991) \\
\hline $\begin{array}{l}\text { Quando se tom nogao de como devo agir, movimontar-se om } \\
\text { um determinado hogr adaptando-se as limitaçes do espapo. }\end{array}$ & $\begin{array}{c}\text { Mour o Staet } \\
(1984)\end{array}$ \\
\hline $\begin{array}{l}\text { Cepacidede de situar-se em funcas da sucessao dos } \\
\text { acontecimentos antes, apos. durante e de durapao dos } \\
\text { intervalos. }\end{array}$ & $\begin{array}{c}\text { Meur e Staes } \\
(1984)\end{array}$ \\
\hline 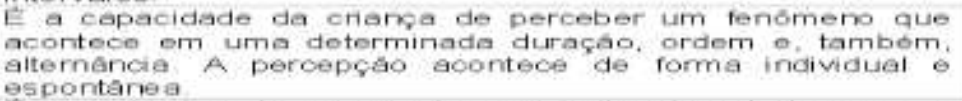 & Boato (1995) \\
\hline $\begin{array}{l}\text { E o onhedmento que a cramce adquire do proprio como e } \\
\text { suas partes por meio desse conhecimento consegue-se } \\
\text { manipular e utilizar o corpo para o relacionamento com o melo } \\
\text { ambiente. }\end{array}$ & $\begin{array}{l}\text { Le Bouloh } \\
\text { (1983) }\end{array}$ \\
\hline
\end{tabular}

Fonte: Aquino et al., (2012, p. 248)

A ciência psicomotora pode contribuir diretamente para desenvolvimento cognitivo infantil e auxiliar no processo de reabilitação de crianças que estejam apresentando dificuldades de aprendizagem (FONSECA, 2018).

A corporalidade através do movimento permite que a criança explore o mundo a sua volta e o conheça, ou seja, para que não se crie um bloqueio nesse indivíduo é de extrema importância desenvolver as noções das crianças sobre o próprio corpo, bem como o seu esquema corporal, sendo esses fatores importantes para 0 desenvolvimento da mesma (SANTOS; CAVALARI, 2010). 


\section{- Aspectos da psicomotricidade no desenvolvimento cognitivo infantil}

A cognição pode ser conceituada como a capacidade do indivíduo de processar informações e transformar em conhecimentos tendo como base um conjunto de habilidades cerebrais como por exemplo a percepção, imaginação, atenção, o raciocínio, a memória (FONSECA, 2018).

A relevância da psicomotricidade dentro do contexto desenvolvimental da criança pode ser evidenciada nos esforços para criação de um ambiente favorável de aprendizagem, considerando os aspectos cognitivos, emocionais e motores ao longo do seu crescimento, tendo como alvo a plena formação do indivíduo (CAVALCANTI, 2015). De acordo com Martins (2014) após o nascimento não é possível uma comunicação clara por parte da criança, pois a mesma só possui de recurso a sua motricidade já que ainda não desenvolveu a linguagem oral e não possui estruturas cognitivas que Ihe possibilite racionalizar suas emoções.

O desenvolvimento cerebral acontece através do corpo humano, apesar de óbvio, vale ressaltar que o cérebro faz parte do corpo e não o contrário, ou seja, o cérebro se desenvolve através de experiências corporificadas, porque a mente é motora, corpórea e experiencial (FONSECA, 2018). Portanto, é possível compreender que problemas associados ao desenvolvimento cognitivo infantil, podem ser amenizados através de ações corpóreas que harmonizem as relações entre corpo, motricidade, cérebro e mente do indivíduo.

Figura 02. Modelo Neuropsicomotor da experiência humana

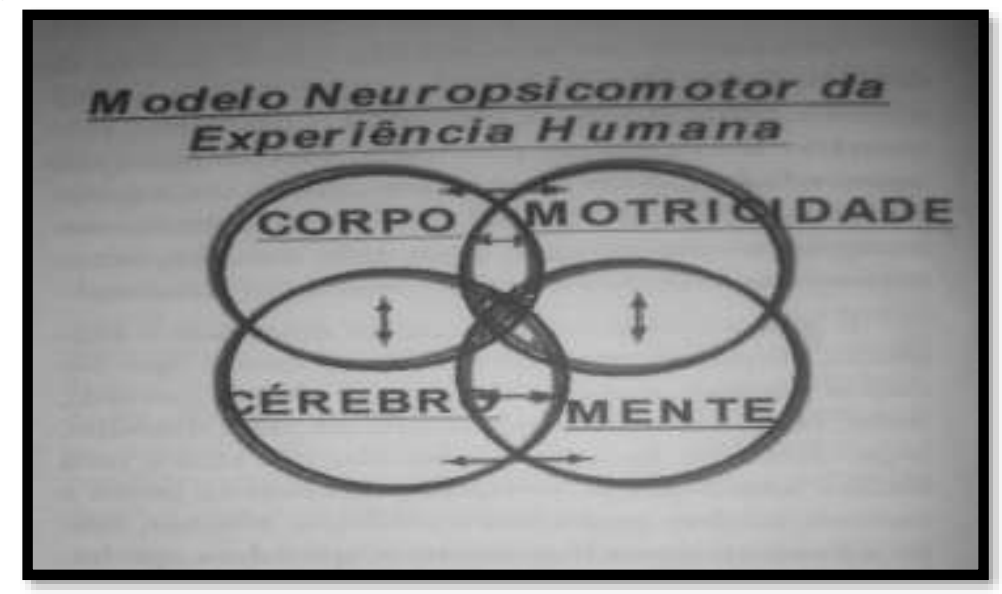

Fonte: Fonseca (2018, p.30) 
Segundo Fonseca (2018) a aprendizagem por ser um processo corporificado, depende de fatores externos diversos, ou seja, da interação do nosso eu (grifo do autor) com o ambiente a nossa volta, sendo dependente da saúde, nutrição, do sono, expressão corporal, além de atividades motoras, lúdicas, desportivas e recreativas.

Nesta vertente, a psicomotricidade evidencia a comunicação do adulto com as crianças e entre elas, utilizando-se de um conjunto de estratégias de intervenção e de ações pedagógicas, auxiliando nos processos de aprendizagem e de desenvolvimento da criança (MACHADO; VINICIUS, 2010).

Fonseca (2018) sinaliza que as funções práxicas estão organizadas de forma hierárquica de maneira que não há como desenvolver determinadas habilidades antes das outras, ou seja, as conquistas neurofuncionais podem ser organizadas da seguinte forma:

Quadro 1. Adaptações neurofuncionais

\begin{tabular}{|ll|}
\hline 1) & Macromotricidade - A postura e marcha bípedes \\
\hline 2) & Micromotricidade - A coordenação motora fina e a produção de instrumentalidade; \\
\hline 3) & Oromotricidade - A comunicação gestual e verbal; \\
\hline 4) & Gafromotricidade - A expressão artística e a expressão escrita; \\
\hline 5) & Criação, retenção, transmissão e utilização do conhecimento, ou seja, é quando o indivíduo \\
consegue atingir a fase de maturação.
\end{tabular}

Fonte: Fonseca $(2018$, p.68)

Em termos de desenvolvimento infantil, todas estas conquistas neurofuncionais adaptativas consistem na incorporalização e internalização sequencialmente. O desenvolvimento inadequado de tais funções pode acarretar em crianças com necessidades desenvolvimentais e necessidades especiais educacionais (FONSECA, 2018).

O desenvolvimento psicomotor inadequado pode acarretar em uma série de problemas que podem ser percebidos pelos professores em sala de aula, como por exemplo a dificuldade de concentração, dificuldades na grafia, letra ilegível ou escrita forte de maneira que rasgue o papel, dificuldades de participar de brincadeiras e jogos, tudo isso porque para a realização de tais atividades se faz necessário noção espacial, lateralidade, e conhecimento do próprio corpo (NEGREIROS, 2018).

Deste modo é evidente a importância de trabalhar o que o autor chama de tripé básico na formação do indivíduo, que seria a afetividade, cognição e 
motricidade por serem interligados como principais contribuidores para que o processo de Ensino-aprendizagem seja efetivo, sendo as oportunidades de exercícios motores e os estímulos cognitivos de suma importância para que se alcance tais resultados (OLIVEIRA; FONSECA, 2017).

\section{- Psicomotricidade nas aulas de educação física}

Segundo Botelle (2016) durante a infância, no período entre 3 e 8 anos de idade as aquisições psicomotoras acontecem de forma mais acelerada e a evolução das mesmas determinam o aprendizado da leitura e da escrita, enquanto as adaptações desenvolvem a consciência dessa criança, para que ela aprenda como se relacionar com o outro, a organizar e controlar seu próprio corpo.

Tanaka e Ferraz (2018) cita que os primeiros estágios de desenvolvimento global de uma criança se dão através da cognição, movimento e experiência. Geralmente o desenvolvimento psicomotor na escola ocorre entre o pré escolar ao ensino fundamental I e II, e é de extrema importância que toda criança passe por todas as etapas em seu desenvolvimento.

A educação psicomotora é considerada como uma ferramenta básica e fundamental para o desenvolvimento infantil, pois por meio dela as crianças podem ajustar os conhecimentos que aprenderam na pré-escola e no ensino fundamental para que possam compreender sua capacidade corporal e de coordenação gestual e ação (DORNELES; BENETTI, 2012).

Xisto e Benetti (2012) ressaltam a relevância da educação psicomotora para a prevenção de dificuldades escolares, como por exemplo, leitura e escrita, afeto, socialização, lateralidade, atenção e funções cognitivas.

Campos (2013) traz a importância do professor de educação física no desenvolvimento de habilidades básicas que serão pré-requisitos para que o processo de ensino-aprendizagem aconteça de forma efetiva, e para que essas crianças não apresentem problemas com aprendizado, já que o mesmo é considerado pelo autor como um processo complexo que exige muito dos educandos. "A busca por ferramentas, de auxílio na aprendizagem escolar tem se tornado multidisciplinar, na 
qual a Educação Física tem papel importante neste processo" (XISTO; BENETTI, 2012, p.1825).

A Base Nacional Comum Curricular (BRASIL, 2017) cita em sua versão mais atualizada os direitos desenvolvimentais e de aprendizagem na educação infantil, dentro da disciplina Educação Física sendo eles: convivência com adultos e outras crianças, brincar de maneiras variadas, em espaços diferentes e companhias diversas, expressar sejam seus questionamentos, emoções, dúvidas, ou descobertas; explorar formas, palavras, movimentos e saberes sobre cultura; participar de forma ativa das atividades propostas pelo professor e do planejamento de atividades como escolha de brincadeiras, entre outros; conhecer-se construindo uma autoimagem positiva de si mesmo, uma identidade pessoal, cultural e social.

De acordo com Gomes e Magalhães (2015) a maior parte das experiências vividas por uma criança acontecem no ambiente educacional, pois é nesse ambiente em que a mesma passa a maior parte dos dias e portanto os profissionais devem estar preparados para oferecer estímulos para que o desenvolvimento que já é natural seja potencializado.

O papel do professor de educação física para o desenvolvimento das capacidades mentais, sociais, físicas e afetivas de uma criança deve estar atrelado à buscas por meios de envolvê-la em atividades que possam gerar prazer em praticar. Sendo assim, é através das aulas de Educação Física que a criança poderá estimular os seus movimentos, socializar com a turma e expor as suas emoções possibilitando a capacidade de pensar, criar e recriar. Já a ludicidade como as brincadeiras, brinquedos e a utilização de objeto nos jogos entram como apoio nesse processo pedagógico nas aulas (AQUINO et al. 2012).

Trazendo um reforço para tal afirmação Coelho (2012) diz que para que as crianças desenvolvam habilidades para lidar com regras e trabalhar em equipe, se faz necessário o uso de brinquedos e brincadeiras pelo professor de Educação Física.

Para Klemper (2013) são considerados elementos psicomotores: o equilíbrio, o esquema corporal, a lateralidade, estruturação temporal e espacial, a coordenação motora grossa e fina, a imagem corporal e as percepções visuais e auditivas.

Existem diversas atividades psicomotoras que podem ser utilizadas nas aulas de Educação Física, que especificamente podem auxiliar no desenvolvimento 
dos elementos psicomotores. A coordenação global ou grossa é responsável por manter o corpo em equilíbrio portanto trabalha movimentos amplos e coloca grupos musculares diferentes em movimento ao mesmo tempo (ANDRADE, 2017). Abaixo alguns exemplos:

- Atividades para coordenação motora grossa: Pega - pega, Amarelinha, Pula Corda, Circuitos, Estátua, Morto ou Vivo, Futebol e Esconde - esconde.

Figura 2. Circuito Psicomotor

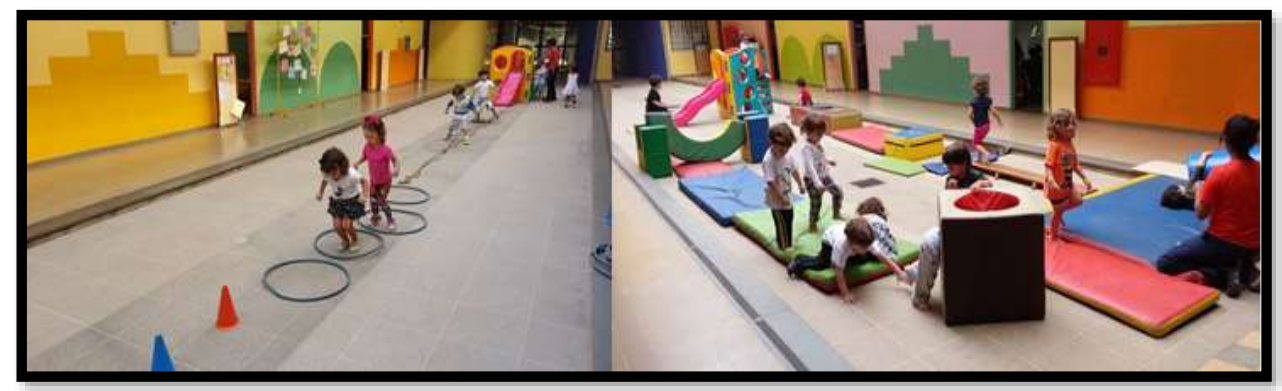

Fonte: Instituto da criança http://www.institutodacrianca.com.br/noticias/listar/circuito-motor-com-omaternal-iiprofessora:-andreaajudante:-rosilene-2013-11-05

A coordenação motora fina é responsável por exercícios refinados trabalhando pequenos músculos com movimentos coordenados auxiliando no aprendizado da linguagem e escrita (ANDRADE, 2017).

- Atividades para coordenação motora fina: colagem de confetes e pinturas, confecção de pulseiras usando miçanga e canudos, pintura e colagem de lã, atividades com figuras para crianças alinharem, exercício de ligar uma figura a outra com pontilhado e colocar grãos ou moedas dentro de cofrinhos.

Figura 3. Atividades com confecção de pulseiras e grãos em cofrinhos.

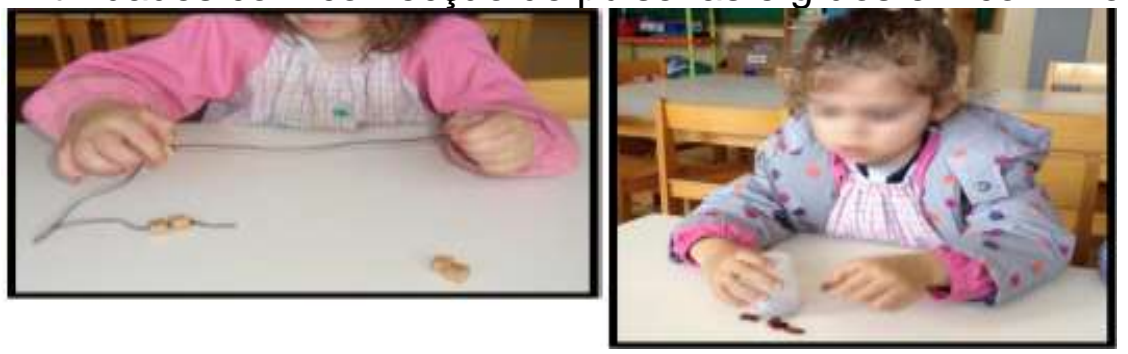

Fonte: Ana Francisca Azevedo Costa (2013). < http://repositorio.ipvc.pt/bitstream/20.500.11960/1392/1/Ana_Costa.pdf> 
A lateralidade está relacionada com a capacidade do indivíduo utilizar o lado dominante do corpo ou que ele tenha maior facilidade para execução de tarefas diárias (INSTITUTO NEUROSABER, 2018).

- Atividades para lateralidade: terra - mar, dança do Saci, chutar bolinha de papel alternando os pés, trilha de pegadas.

Figura 4. Trilha de pegadas.

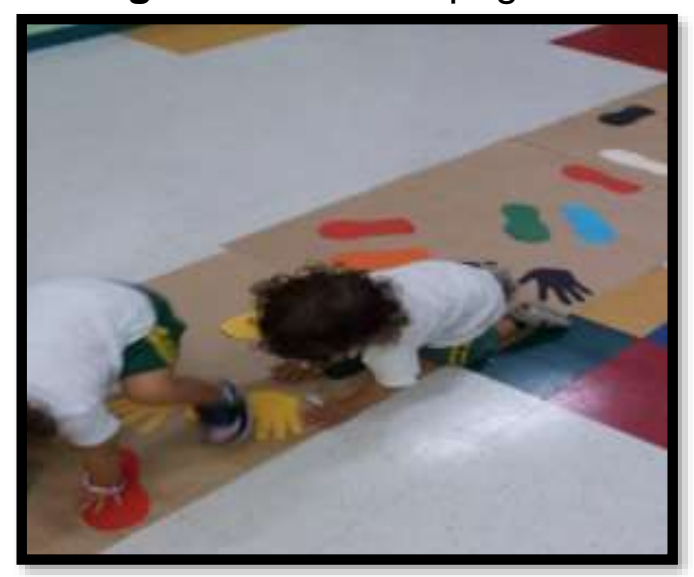

Fonte: Site do Colégio Arci Pimpolho

<https://arcipimpolho.com.br/atividades.asp?idativ=397\&ano=2020\&ciclo=421>

- Atividades para o equilíbrio: andar sobre linhas, Pulo certeiro (pular dentro do círculo), brincar na cama elástica, manter - se na ponta dos pés com braços rente ao tronco e pernas unidas, fazer o $4 \mathrm{com}$ a perna, corrida de Saci.

Figura 5. Atividade pulo certeiro

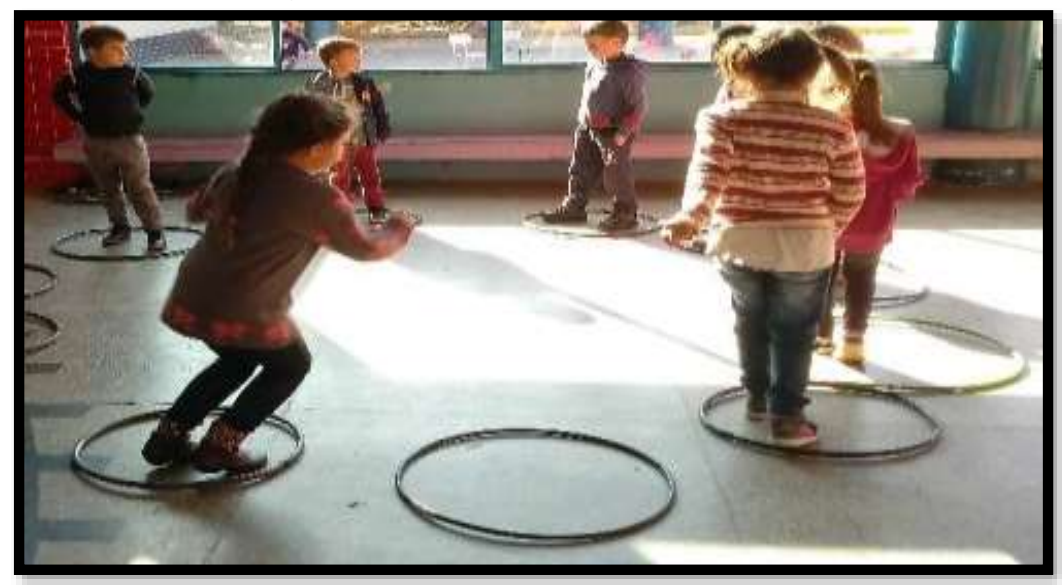

Fonte: Prefeitura municipal Barra Funda. <https://barrafunda.rs.gov.br/noticias/item/oficina-depsicomotricidade-na-escola-raio-de-sol.html> 
A estruturação espaço - temporal representam os elementos básicos do aprendizado e da função cognitiva, pois está implícita na escrita, leitura, ritmo e cálculo (PATEL, 2012).

- $\quad$ Atividades para a Estruturação Espaço - Temporal e Ritmo: saltar com obstáculos, correr pra todas as direções, saltar nos quadriculados do chão, organizar salas, tapete geométrico, pular corda, criando sons,

Figura 6. Tapete geométrico.

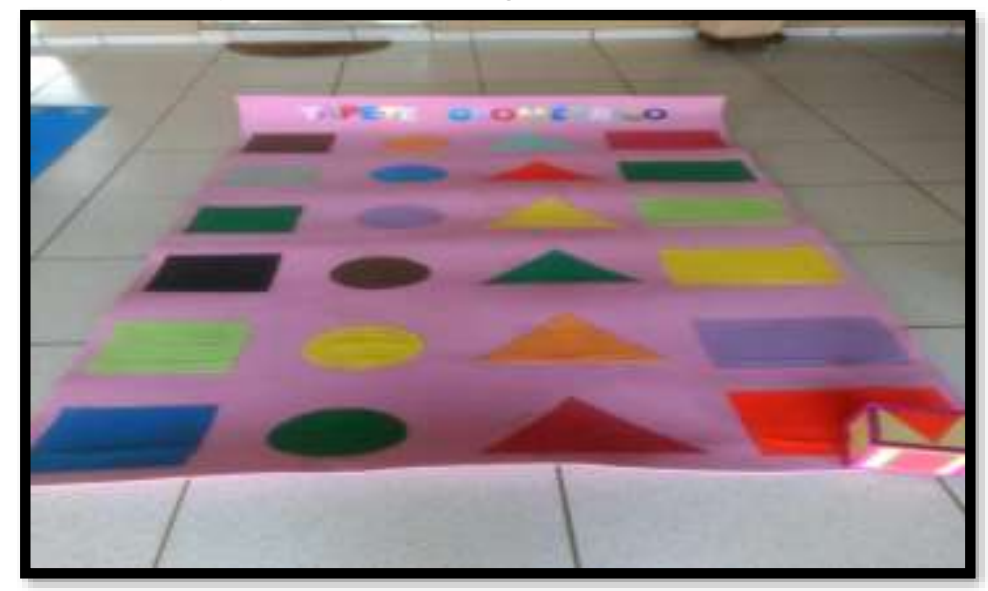

Fonte: Site Núcleo do Conhecimento < https://www.nucleodoconhecimento.com.br/educacao/importancia-da-psicomotricidade>

Figura 7. Estruturação Espaço - temporal

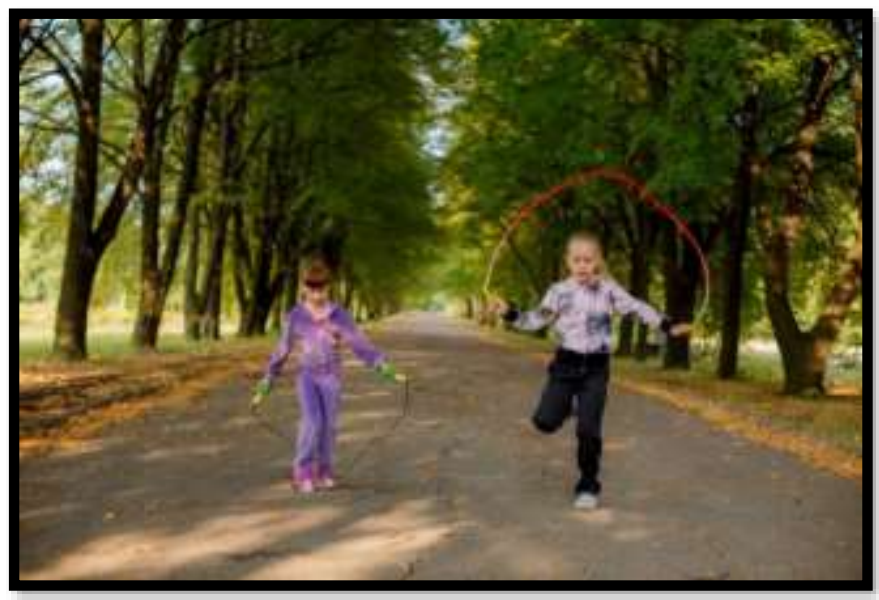

Fonte: Blog Psicomotricidade Infantil <

http://psicomotricidaedfisica.blogspot.com/2017/04/psicomotricidade-infantil.html>

É a noção e o conhecimento que a criança tem sobre o seu próprio corpo, das suas partes e dos seus movimentos (Voll, 2018). 
Atividades para Esquema Corporal: Pintar no papel a sua imagem, dar quebra - cabeça do corpo humano incompleto para crianças.

Figura 8. Quebra cabeça incompleto

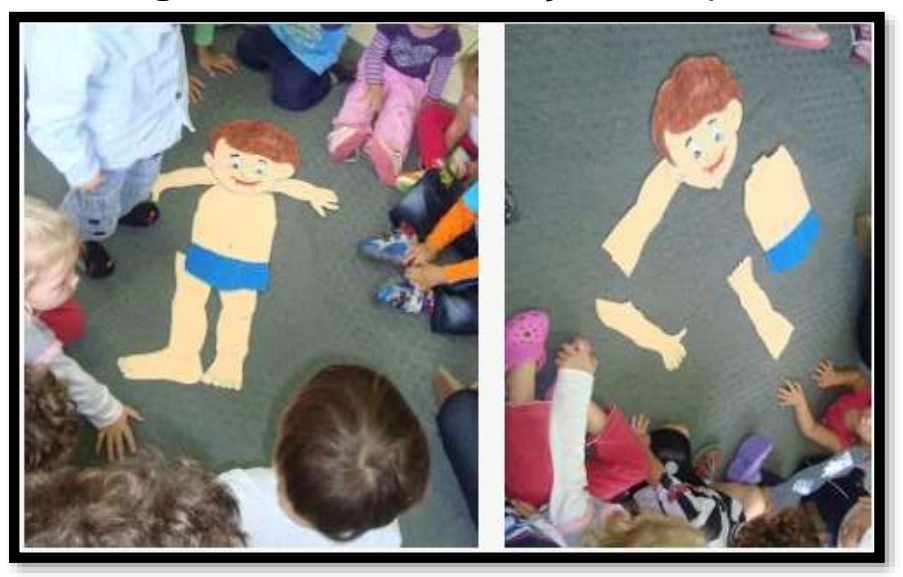

Fonte: Atividades pedagógicas < https://atividadespedagogicas.net/2017/10/esquema-corporal-naeducacao-infantil.html>

\section{Considerações finais}

Considera-se após o estudo realizado, que há uma concordância na literatura de que as práticas psicomotoras trazem diversos benefícios para o desenvolvimento da criança, auxiliando na sua formação global.

A psicomotricidade enquanto ciência se preocupa com o estudo de áreas diferentes do indivíduo e seus principais focos de investigação são a motricidade, a afetividade e a cognição, e o uso dessa ciência como ferramenta de intervenção dentro da Educação Física é benéfica e resulta positivamente no aprendizado das demais disciplinas. Pudemos perceber ao longo desse trabalho, como as experiências corpóreas afetam a cognição, sendo assim foi possível também refletir sobre intervenções para o reparo de déficits intelectuais através de ações corporificadas.

Notoriamente o professor tem um papel importante nesse processo, pois é através da apropriação dessa ferramenta e uso correto da mesma, que se faz possível um processo de ensino-aprendizagem efetivo. 


\section{REFERÊNCIAS}

$\begin{array}{lccccr}\text { Associação } & \text { Brasileira } & \text { de } & \text { Psicomotricidade } & & < \\ \text { https://psicomotricidade.com.br/sobre/o-que-e-psicomotricidade/>Acesso } & 28 & \text { Out }\end{array}$ 2020.

ANDRADE, Ana. A importância do estímulo ao desenvolvimento da coordenação motora global fina. Universidade Estadual de Goiás 13 e 14 de novembro de 2017.

AQUINO, M. de et al. Psicomotricidade como ferramenta da educação física na educação infantil. Revista Bras. de Futsal e Futebol, São Paulo, v. 4, n. 14, p. 245257. Jan/Dez. 2012. Disponível em:

<http://www.rbff.com.br/index.php/rbff/article/view/145>. Acesso em: 23 Set. 2020.

BESSA, Larissa; MACIEL, Rosana. A importância da Psicomotricidade no Desenvolvimento das Crianças nos anos iniciais. Revista Cientifica Multidisciplinar Núcleo do Conhecimento. Ano 01, Ed. 01, Vol.12, pp. 59-78, dezembro de 2016.

BOTELLE, Andréa. Psicomotricidade: a importância do lúdico na infância. $1^{\underline{a}}$ Edição. Rio de Janeiro: Editora Autografia, 2016.

BRASIL. Base Nacional Comum Curricular (BNCC). Educação é a Base. Brasília, MEC/CONSED/UNDIME, 2017.

CAMPOS, Aline Mara Araujo Dias. A importância da psicomotricidade para a educação infantil, 2013. Disponível em: <https://www.portaleducacao.com.br/conteudo/artigos/esporte/a-importancia-dapsicomotricidade-para-educacao-infantil/48643> Acesso em 24 de Out. 2020.

CAVALCANTI, L. Psicomotricidade e sua importância para o desenvolvimento cognitivo, afeito e social da criança, 2015. Disponível em $<$ https://www.revistaacademicaonline.com/products/psicomotricidade-e-sua importancia-para-o-desenvolvimento-cognitivo-afetivo-e-social-da-crianca/> Acesso em 12 de Out. 2020.

COELHO, Elisangela Veiga do Prado. Psicomotricidade na educação infantil. Curitiba, 2012.

COSTA JR, Dirceu. Psicomotricidade e Desenvolvimento Motor. Valinhos: 2017.

DORNELES, L. R., BENETTI, L.B. A psicomotricidade como ferramenta de aprendizagem. Monografias Ambientais REMOA/UFSM, Universidade Federal do Pampa, Uruguaiana, n. 8, 2012, p. 1775-1786. Disponível em: http://cascavel.ufsm.br/revistas/ojs-2.2.2/index.php/remoa/index. Acesso em: 10 out. 2020. 
FONSECA, Vitor da. Psicomotricidade: uma visão pessoal. Constr. psicopedag., São Paulo, v. 18, n. 17, p. 42-52, dez. 2010 . Disponível em <http://pepsic.bvsalud.org/scielo.php?script=sci_arttext\&pid=S1415-

$69542010000200004 \&$ lng=pt\&nrm=iso >. acessos em 12 out. 2020.

FONSECA, Vitor da. Neuropsicomotricidade: Ensaio sobre as relações entre corpo, motricidade, cérebro e mente. Rio de Janeiro: Editora Wak, 2018.

GOMES, A; MAGALHÃES, N; MAIA, P. Avaliação do desenvolvimento motor na fase fundamental de crianças em uma instituição de ensino de Pirajuí/SP estudo comparativo, Lins, 2015.

Instituto Wallon Educacional. Psicomotricidade, movimento e recreação.

LENT, R. Cem bilhões de neurônios? Conceitos fundamentais de neurociência. 2. ed. São Paulo: Atheneu, 2010. 848 p.

KLEMPER, N.D. A psicomotricidade como ferramenta na escola infantil. Monografia para licenciatura plena em pedagogia, Lins- SP, 2013.

MACHADO, José Ricardo Martins; VINICIUS, Marcos. Recriando a psicomotricidade. Rio de Janeiro: Sprint, 2010.

MARTINS, C.M. A Psicomotricidade como forma de contribuição para a aprendizagem na Educação Infantil e séries iniciais do ensino fundamental I.Trabalho de conclusão de curso (Pós Graduação em Psicomotricidade) - Centro Universitário Assunção UNIFAI, São Paulo, 2014

Instituto Neurosaber.A importância da Psicomotricidade para Educação Infantil. Disponível em: <https://institutoneurosaber.com.br/a-importancia-dapsicomotricidade-para-educacao-infantil/> Acesso em 16 de Set. 2020.

OLIVEIRA, Lelimar Lopes de; FONSECA, Maria da Conceição Vinciprova. A IMPORTÂNCIA DOS ESTÍMULOS: AFETIVO, COGNITIVO E MOTOR NO DESENVOLVIMENTO DA CRIANÇA DESDE SUA TENRA IDADE. Artefactum: REVISTA DE ESTUDOS EM LINGUAGEM E TECNOLOGIA, Rio de Janeiro, n. 01, p. 1-10, 2017.

NEGREIROS, F. Psicomotricidade e práticas pedagógicas no contexto da Educação Infantil: uma etnografia escolar. Revista Educação e Emancipação, São Luís, v. 11, n. 1, jan./abr. 2018. Disponível em: <file:///C:/Users/Pc\%20Naty/Downloads/Psicomotricidade_e_praticas_pedagogicas_ no_context.p> Acesso em 12 de Out. 2020.

OLIVEIRA, Andreza, F, S; SOUZA, Jose, M. A importância da psicomotricidade no processo de aprendizagem infantil. Revista Fiar: Revista Núcleo de Pesquisa e Extensão Ariquemes, v.2, n.1, p.125-146, 2013. 
PATEL, V. Psicomotricidade. Uniasselvi. 2012.

RAMOS, Camila; FERNADES, Marcela. A importância de desenvolver a psicomotricidade a infância. EFDeportes.com, revista digital. Buenos Aires, fevereiro de 2011. Disponível em < https://www.efdeportes.com/efd153/a-importanciaa-psicomotricidade-na-infancia.htm> Acesso em 25 out. 2020

SANTOS, E. L. S; CAVALARI, N. Psicomotricidade e educação infantil. Caderno Multidisciplinar de Pós-Graduação da UCP, Pitanga, v. 1, n. 3, p. 149-163, 2010.

TANAKA, Camila Chaves; FERRAZ, Marcelo Antônio. A psicomotricidade nas aulas de Educação Física: sob a ótica dos professores das escolas públicas e particulares. São Paulo, 2018.

VOLL, G. Atuação da Educação Física no desenvolvimento da psicomotricidade. 1 out. 2018. Disponível em <https://blogeducacaofisica.com.br/educacao-fisicapsicomotricidade/> Acesso em 15 out.2020.

XISTO, P.B., BENETTI, L.B. A psicomotricidade uma ferramenta de ajuda aos professores na aprendizagem escolar. Monografias Ambientais. REMOA/UFSM ,Universidade Federal do Pampa, Uruguaiana, n. 8, 2012, p. 1824-1836.

Manuscrito recebido em: 06 de novembro de 2020

Aprovado em: 22 de dezembro de 2020

Publicado em: 22 de dezembro de 2020 